\section{RETHINKING URBAN DIVERSITY}

With their socio-physical, socio-economic, sociocultural, and sociopolitical presence cities have always been highly differentiated spaces expressive of heterogeneity, diversity of activities, entertainment, excitement, and pleasure. They have been (and still are) melting pots for the formulation of and experimentation with new philosophies and religious and social practices. They produce, reproduce, represent, and convey much of what counts today as culture, knowledge, and politics. Urban spaces within cities are no exception; they are places for the pursuit of freedom, un-oppressed activities and desires, but also ones characterized by systematic power, oppression, domination, exclusion, and segregation. In dealing with these polar qualities diversity has become one of the new doctrines of city planners, urban designers, and architects. It continues to be at the center of recent urban debates. Little is known, however, on how urban space diversity can be achieved.

In recent rhetoric, diversity denotes in generic terms a mosaic of people who bring a variety of ethnic and cultural backgrounds, styles, perspectives, values and beliefs as assets to the groups and organizations with which they interact. However, in urban discourses it has been addressed as having multiple meanings that include mixing building types, mixing physical forms, and mixing people of different social classes, racial and ethnic backgrounds. While some theorists attribute diversity to the socio-physical aspects of homogeneity within heterogeneity, social differentiation without exclusion, variety, and publicity, others associate it with socio-political aspects of assimilation, integration, and segregation. While some of these meanings represent a concern for a specific group of professionals including architects and urban designers, urban planners, cultural analysts and abstract theorists, they all agree that each meaning or aspect of diversity is linked to the others; they all call for strategies for urban development that stimulate socio-physical heterogeneity.

With the goal of unveiling lessons learned on urban diversity from various cases in different parts of the world, this issue of Open House International selects ten papers after a rigorous review process. The edition encompasses several objectives. It aims at providing a conceptualization of urban diversity while articulating its underlying contents and mechanisms by exploring the variety of meanings adopted in the urban literature. In essence, it attempts to establish models for discerning urban space diversity while mapping such models on selected case studies from Europe, African, and the Middle East.

In the context of Europe two papers address urban diversity on different scales. The discussion of diversity in the work of Thierstein and Weise is undertaken at a regional scale where the regeneration of former industrial sites is regarded as a unique opportunity to actively direct urban development in the context of Germany. Based on the notion that urban form shapes urban life and vice versa, Thierstein and Weise suggest a framework that integrates the material city and the immaterial relations that develop at different scales that range from the plot, the quarter, to the city, the region, or to the polycentric megacity region. Along the same line of thinking Pinto and Remesar argue that public space is structured in a cohesive system on different territorial scales within the city, forming a 'network of networks'. They suggest a method that assesses the cohesion of public space networks within the urban structure of the neighbourhood as well as the surrounding networks. In this respect, two cases are selected from Barcelona to delineate that urban cohesion is conceptualized to integrate the physical form of the city and the city's socioeconomic and socio-cultural dynamics.

Debating urban diversity in cities of the Arabian Peninsula, the work of Salama and Gharib; Mahgounb and Qawasmeh; and Alrouf, illustrates different narratives on the urban condition. Salama and Gharib argue that little attention has been paid to several growth aspects in the city of Doha, including the understanding of urban space diversity and the resulting inhabitants' spatial experience, their attitudes toward emerging urbanized spaces. Their work explores urban spaces as perceived and experienced by different groups through an investigation of a number of key spaces and by utilizing attitude surveys. They assert the conjecture that urban spaces are perceived and experienced differently by different groups based on their gender, age, and cultural background and conclude with suggestions toward a more inclusive 
approach to the design of the city's urban spaces. IN the same context, Mahgoub and Qawasmeh maintain that urban spaces define limits and boundaries for social experiences and interaction based on the cultural and economic background. They propose important measures to improve the quality of urban experience of the diverse cultural groups within Doha. On the other hand, Alraouf offers an interpretation of how traditional markets (Souqs) can be conceived as a catalyst for achieving urban diversity. He introduces important issues that pertain to cultural diversity and national identity as they relate to two cases from the cities of Doha and Manama.

In the context of the African Continent, the work of Garba and Landman manifests a number of aspects related to diversity. Taking the case of the traditional city of Zaria, Nigeria, Garba examines patterns of diversity while identifying critical issues facilitate the quest for urban diversity. These include place attractiveness, appropriateness of development scale and embedded settings for activities, and regime of access and participation. In the context of South Africa, Landman's work explores the multiple meanings of place diversity with an emphasis on medium density mixed housing developments. Her work highlights a number of paradoxes that emerge as a result of context-specific realities. Yes, it articulates key parameters toward designing for diversity.

Other papers in this issues include cases and discussion on key issues related urban diversity. This is evident in the work of Christine Mady who discusses to the temporal dimension in public spaces of Beirut, the work of Fodil Fadli who discusses spatial needs of a Muslim minority community in the context of Northern Ireland, and Drucker and Gumpert who offer an articulation on the relationship between digital technology and social interaction in the public space.

It is believed that the ten papers selected in this issue of Open House International advance the literature on urban diversity. While offering cases from specific contexts in Europe, African, and the Middle East, they invigorate previous knowledge generated from urban literature and assert the need to continuously re-assess the urban condition in the quest for urban diversity.

\section{Prof. Dr. Ashraf M. Salama}

Department of Architecture and Urban Planning Qatar University, Doha, Qatar. asalama@qu.edu.qa, asalama@gmail.com

\section{Prof. Dr. Alain Thierstein}

Department of Architecture Institute for Spatial and Territorial Development Arcisstrasse 21, 80333 Muenchen Germany. thierstein@tum.de 